\title{
A prospective trial of intraoperative tissue oxygenation measurement and its association with anastomotic leak rate after Ivor Lewis esophagectomy
}

\author{
Prasad S. Adusumilli ${ }^{1,2}$, Marom Bikson ${ }^{3}$, Nabil P. Rizk ${ }^{1}$, Valerie W. Rusch ${ }^{1}$, Boris Hristov ${ }^{1}$, \\ Rachel Grosser ${ }^{1}$, Kay See Tan ${ }^{4}$, Inderpal S. Sarkaria ${ }^{1}$, James Huang ${ }^{1}$, Daniela Molena ${ }^{1}$, David R. Jones ${ }^{1}$, \\ Manjit S. Bains ${ }^{1}$
}

${ }^{1}$ Thoracic Service, Department of Surgery, ${ }^{2}$ Center for Cell Engineering, Memorial Sloan Kettering Cancer Center, New York, NY, USA; ${ }^{3}$ Department of Biomedical Engineering, The City College of New York, New York, NY, USA; ${ }^{4}$ Department of Epidemiology and Biostatistics, Memorial Sloan Kettering Cancer Center, New York, NY, USA

Contributions: (I) Conception and design: PS Adusumilli; (II) Administrative support: PS Adusumilli, M Bikson, VW Rusch, DR Jones, MS Bains; (III) Provision of study materials or patients: PS Adusumilli, NP Rizk, VW Rusch, IS Sarkaria, J Huang, D Molena, DR Jones, MS Bains; (IV) Collection and assembly of data: PS Adusumilli, B Hristov, R Grosser, KS Tan; (V) Data analysis and interpretation: PS Adusumilli, MS Bains, NP Rizk, KS Tan; (VI) Manuscript writing: All authors; (VII) Final approval of manuscript: All authors.

Correspondence to: Prasad S. Adusumilli, MD, FACS, FCCP. Deputy Chief and Attending, Thoracic Service, Department of Surgery; Vice Chair, Translational Research, Department of Surgery; Director, Mesothelioma Program; Head, Solid Tumors Cell Therapy, Cellular Therapeutics Center; Memorial Sloan Kettering Cancer Center, 1275 York Avenue, New York, NY 10065, USA. Email: adusumip@mskcc.org.

\begin{abstract}
Background: Anastomotic leak following Ivor Lewis esophagectomy is associated with increased morbidity/mortality and decreased survival. Tissue oxygenation at the anastomotic site may influence anastomotic leak. Methods for establishing tissue oxygenation at the anastomotic site are lacking.

Methods: Over a 2-year study period, 185 Ivor Lewis esophagectomies were performed. Study participants underwent measurement of gastric conduit tissue oxygenation at the planned anastomotic site using the wireless pulse oximetry device. Associations between anastomotic leaks or strictures and tissue oxygenation levels were analyzed using Wilcoxon rank sum test or Fisher's exact test.

Results: Among study participants ( $\mathrm{n}=114$ ), median gastric conduit tissue oxygenation level was 92\% (range, $62-100 \%)$. There were 8 (7.0\%) anastomotic leaks and 3 (2.6\%) strictures. Analysis of tissue oxygenation as a continuous variable showed no difference in median tissue oxygenation in patients with and without leaks (98\% and 92\%; $\mathrm{P}=0.2$ ) and stricture formation ( $89 \%$ and $92 \% ; \mathrm{P}=0.6$ ). Analysis of tissue oxygenation as a dichotomous variable found no difference in anastomotic leak rates $[7.5 \%(\mathrm{n}=93)$ in $>80 \% v s .0 \%(\mathrm{n}=20)$ in $\leq 80 \% ; \mathrm{P}=0.3$ ]. There were no significant differences in leak rates in concurrent study nonparticipants.

Conclusions: No significant association was observed between intraoperative tissue oxygenation at the anastomotic site and subsequent anastomotic leak or stricture formation among patients undergoing Ivor Lewis esophagectomy.
\end{abstract}

Keywords: Esophageal cancer; tissue oxygenation; anastomotic leak; tissue perfusion

Submitted Sep 05, 2019. Accepted for publication Nov 15, 2019.

doi: $10.21037 /$ jtd.2020.02.58

View this article at: http://dx.doi.org/10.21037/jtd.2020.02.58

\section{Introduction}

In patients with local and locoregionally advanced esophageal and gastroesophageal junction cancers, an esophagogastrectomy is an important component of their treatment regimen. The most morbid complication associated with Ivor Lewis esophagectomies is anastomotic 
Table 1 Publications on tissue oxygenation measurement

\begin{tabular}{|c|c|c|c|c|c|c|c|c|}
\hline Article & $\mathrm{N}$ & Year & $\begin{array}{l}\mathrm{TiO}_{2} \\
\text { evaluation }\end{array}$ & $\begin{array}{l}\text { Type of } \\
\text { surgery }\end{array}$ & $\begin{array}{c}\text { Tissue } \\
\text { oxygenation } \\
\text { measurement- } \\
\text { objective }(\mathrm{O}) \\
\text { or subjective }(\mathrm{S})\end{array}$ & $\begin{array}{l}\text { Registered } \\
\text { clinical } \\
\text { trial }\end{array}$ & $\begin{array}{l}\text { Primary } \\
\text { outcome }\end{array}$ & Conclusions \\
\hline Schilling et al. & 11 & 1996 & US doppler & Esophagectomies & $S$ & No & $\begin{array}{l}\text { US Doppler } \\
\text { blood flux }\end{array}$ & $\begin{array}{l}\text { Blood flux decreases as } \\
\text { gastric conduit is created }\end{array}$ \\
\hline Karliczek et al. & 77 & 2009 & $\begin{array}{l}\text { Visible light } \\
\text { spectroscopy }\end{array}$ & Colorectal & $\mathrm{O}$ & No & $\begin{array}{l}\mathrm{TiO}_{2} \text { of leak } \\
\text { vs. no leak } \\
\text { groups }\end{array}$ & $\begin{array}{l}\text { Lack of rise in } \mathrm{TiO}_{2} \text { after } \\
\text { creation of anastomosis is } \\
\text { associated with increased } \\
\text { leaks }\end{array}$ \\
\hline Pham et al. & 23 & 2011 & $\begin{array}{l}\text { Optical fiber } \\
\text { spectroscopy }\end{array}$ & Esophagectomies & $\mathrm{O}$ & No & $\begin{array}{l}\mathrm{TiO}_{2}, \mathrm{BVF} \text { and } \\
\text { all anastomotic } \\
\text { complications }\end{array}$ & $\begin{array}{l}\text { Large drop in } \mathrm{TiO}_{2} \\
\text { during conduit creation } \\
\text { corresponded to leaks }\end{array}$ \\
\hline Campbell et al. & 90 & 2015 & $\begin{array}{l}\text { Indocyanine } \\
\text { dye + US } \\
\text { doppler }\end{array}$ & Esophagectomies & S & No & $\begin{array}{l}\text { Leak rates } \\
\text { before and } \\
\text { after protocol } \\
\text { implementation }\end{array}$ & $\begin{array}{l}\text { Noted a decrease in leak } \\
\text { rate after implementation } \\
\text { of protocol }\end{array}$ \\
\hline Adusumilli et al. & 114 & 2016 & $\begin{array}{l}\text { Reflectance } \\
\text { pulse } \\
\text { oximetry }\end{array}$ & Esophagectomies & $\mathrm{O}$ & Yes & $\begin{array}{l}\mathrm{TiO}_{2} \text { of leak vs. } \\
\text { no leak groups }\end{array}$ & $\begin{array}{l}\text { No difference was noted } \\
\text { in } \mathrm{TiO}_{2} \text { between the two } \\
\text { groups }\end{array}$ \\
\hline
\end{tabular}

leak, with a reported incidence of $0 \%$ to $26 \%$ (1-5). Patients with an anastomotic leak have a mortality rate 3 times greater than patients without one and in those who survive their perioperative course three-year survival is half of that in patients who did not have an anastomotic leak (1).

The most important step necessary to minimize risk of anastomotic leaks is using generally accepted surgical techniques, such as minimizing tissue tension and approximating mucosa to mucosa. Other factors, such as anastomotic technique (6) and use of preoperative therapy (7), have not been found to be associated consistently with incidence of anastomotic leaks. One potential contributing factor to incidence of anastomotic leaks is variability of tissue oxygenation at the anastomotic site (8). When mobilizing the gastric conduit, the short gastric arteries, the left gastric artery, the left gastroepiploic artery, and, less frequently, the right gastric artery are sacrificed; the consequence is relative hypo-perfusion of the conduit.
Moreover, the anastomotic site tends to be in regions most distal to the stomach's main residual blood supply, which is the right gastroepiploic artery.

In creating an anastomosis, surgeons minimize tension on it and evaluate it for good perfusion, usually by visual inspection only. A drawback of visual inspection for perfusion compromise is that it is subjective and there can be poor perfusion without gross physical changes (9). Several modalities, such as Doppler ultrasound (10) and intravenous fluorescent dye (9), have been used to help identify poor perfusion objectively. To measure tissue oxygenation directly rather than by utilizing tissue perfusion as an indirect measure, there have been previous studies using laser Doppler flowmetry (11) and spectroscopy (12-14). While these studies suggested a possible correlation between conduit oxygenation and complications, they were underpowered-the largest study evaluated 23 patients retrospectively (Table 1) —and no definite conclusions 
Table 2 Comparison of current oximeter options

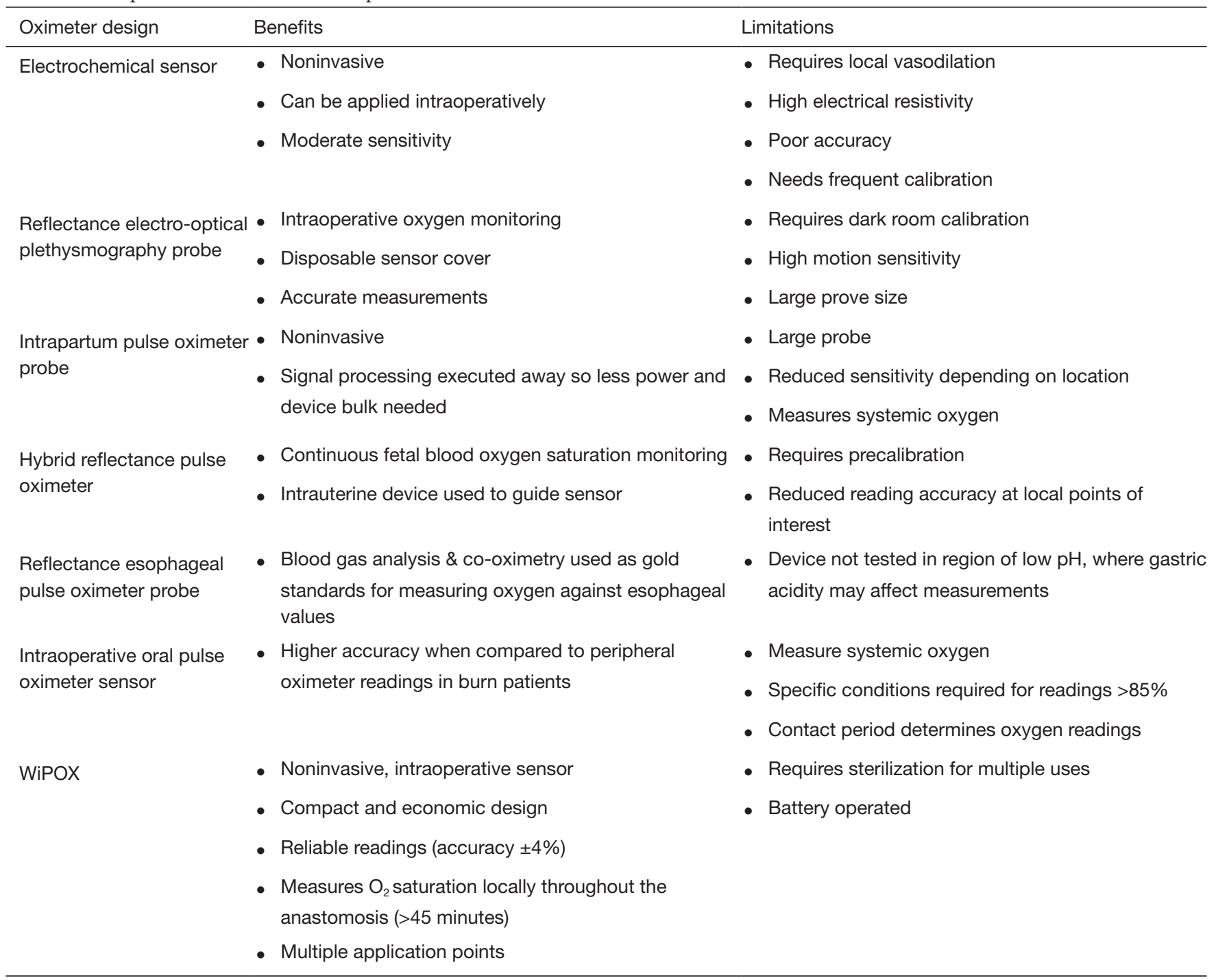

were drawn. Of the few studies with objective tissue oxygenation measurements, some found a link between low tissue oxygenation and anastomotic complications while others found paradoxically normal and even elevated tissue oxygenation in the anastomotic leak group (15). To date, there have been no prospective clinical trials that have demonstrated an objective method for establishing accurate tissue oxygenation at the anastomotic site.

Following evaluation of commercially available devices for measuring tissue oxygenation at extra-thoracic sites, we found no device that could be used reliably during an Ivor Lewis esophagectomy (Table 2). Subsequently, we (I) designed a handheld wireless pulse oximetry (WiPOX) device capable of real-time monitoring of serosal and mucosal tissue oxygenation with data transmission to standard intraoperative monitors; (II) constructed the WiPOX device using materials that met FDA regulations for intraoperative use and reuse; (III) performed accuracy testing in human surface tissue (skin) by comparing the WiPOX device to standard pulse oximeters; and (IV) tested WiPOX efficacy for detection of early tissue hypoxia in stomach, intestines, and kidneys of anesthetized rats and swine (16). We further developed the WiPOX device to a handheld, Ivor Lewis esophagectomy-specific, ergonomic design that has a real-time display and feedback for surgeon confidence. The WiPOX device was then optimized to measure tissue oxygenation reliably at various $\mathrm{pH}$ levels, temperatures, contact force, and interference by blood 

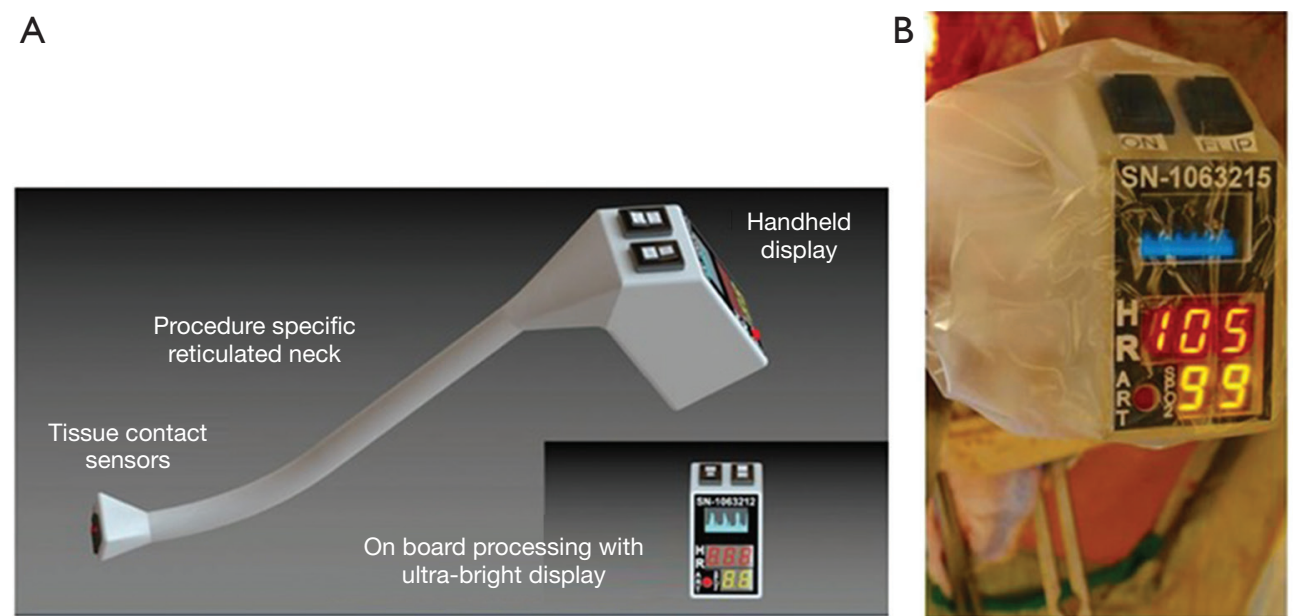

Figure 1 Wireless Pulse Oximetry (WiPOX) device (A) optimized for measurement of gastric conduit tissue oxygenation intra-operatively. The tissue contact sensors measure the tissue oxygenation and display the number along with simultaneous measurement of the heart rate along with the pulsatile oxygenation wave form for measurement reliability (B).

or body fluids (Figure 1A). Subsequently, we conducted a feasibility study in 12 patients who were undergoing an Ivor Lewis esophagectomy and observed that, after mobilization of the stomach, the WiPOX device was able to detect, on average, a $10 \%$ difference in tissue oxygenation at the eventual anastomotic site compared with the pre-mobilized conduit. It was also able to detect that there was a higher likelihood of anastomotic leaks in patients with a WiPOX measured tissue oxygenation saturation of $\leq 80 \%$ (range, 59-95\%); the range in patients without an anastomotic leak was $80 \%$ to $99 \%$ ) (17). Using the WiPOX device did not interfere with surgical procedure flow given the rapidity of obtaining the measurements (approximately 30 seconds per measurement). These observations prompted us to conduct a prospective clinical trial.

In our prospective trial, we used the WiPOX device to measure intraoperative tissue oxygenation levels at the gastric conduit planned anastomotic site prior to anastomosis of patients who were undergoing Ivor Lewis esophagectomies and correlated tissue oxygenation values obtained with postoperative complications. The device uses reflectance pulse oximetry technology to measure local tissue oxygenation and heart rate along with oxygenation wave form. We utilized the WiPOX device to assess the primary endpoint, anastomotic leaks (short term outcome), and the secondary endpoint, strictures (long term outcome). Our hypothesis was that these complications would be correlated with lower operative tissue oxygenation of the gastric conduit.

\section{Methods}

\section{Study cohort}

Our prospective clinical trial (IRB\# 11-192) was approved by the Institutional Review Board of Memorial Sloan Kettering Cancer Center. This single center trial was conducted over a 2-year period between July 2012 and July 2014. Informed consent was obtained from all prospective patients. Preoperative demographics were collected, which included age, sex, co-morbidities, and whether patients received preoperative chemotherapy or chemoradiation therapy.

\section{Inclusion and exclusion criteria}

All patients who were undergoing minimally invasive or open Ivor Lewis esophagectomies were enrolled. The following patients were excluded from the study: (I) patients who did not undergo an Ivor Lewis esophagectomy for esophageal cancer (example transhiatal esophagectomy); (II) patients who were undergoing reoperative surgery; (III) patients with an aborted Ivor Lewis esophagectomy; or (IV) patients who died from non-surgical complications prior to a 60-day follow-up period. All of the patients who underwent the surgical procedure had a tumor at the lower end of the esophagus; end-to-side circular stapler anastomosis was performed at the level of the azygos vein. The width of the conduit varied among surgeons (4 to $8 \mathrm{~cm})$. 


\section{Intervention}

Seven surgeons participated in our study. The thoracic surgical operating experience of the surgeons varied between 3 and 30 years. During the surgery, once the gastric conduit was mobilized and the anastomotic site was identified by the surgeon, the WiPOX device was presented to the surgical fellow who took a single tissue oxygenation measurement on the serosal surface of the planned anastomotic site. The measurement was deemed accurate when the heart rate reading by the device matched (within 5 beats per minute) the heart rate on the operating room monitors. Additionally, we were careful to only record the measurement when there was a pulsatile oxygenation wave form on the display (Figure 1B). Tissue oxygenation levels, systemic oxygen saturation, heart rate, and blood pressure were all recorded at the time of the reading. Surgeons were blinded to the reading.

\section{Study objectives}

The primary objective was to determine whether there was an association between tissue oxygenation levels measured using the WiPOX device at the anastomotic site and incidence of anastomotic leaks after an Ivor Lewis esophagectomy. The secondary objectives were: (I) to correlate various demographics (i.e., age, co-morbidities, and smoking history) and clinical variables (i.e., preoperative therapy, intra-operative blood pressure, and systemic oxygen saturation) with tissue oxygenation at the anastomotic site; and (II) to correlate anastomotic site tissue oxygenation with the post-discharge incidence of stricture.

\section{Post-operative surveillance}

Post-operatively, all complications were recorded and graded according to the standard Common Terminology Criteria for Adverse Events (CTCAE) v4.0 criteria. Both symptomatic and asymptomatic anastomotic leaks within the first 30-day post-operative period were recorded. We defined an anastomotic leak as any clinical evidence of a leak (enteric contents in the peri-anastomotic drains or interventional radiology guided drainage of a collection containing enteric contents) or radiographic evidence of a leak (on CT scan with oral contrast extravasation or barium esophagram showing extravasation). Additionally, postdischarge patients were followed for 6 months and any postoperative strictures that required endoscopic dilation were also recorded.

\section{Statistical analysis}

Based on our pilot data and estimation that $30 \%$ of the patients will have low tissue oxygenation levels at the anastomotic site, a sample size of 111 patients was required to provide $90 \%$ power for detecting a $30 \%$ absolute risk reduction in the incidence of anastomotic leaks between patients with low and normal tissue oxygenation levels ( $40 \%$ vs. $10 \%$, respectively), with two-sided type 1 error of $5 \%$. Demographic and clinical characteristics of patients are summarized by anastomotic leak status. The correlation between systemic and WiPOX-recorded heart rate as well as the correlation between systemic pulse oximetry and WiPOX-recorded oxygenation were quantified by Spearman correlation coefficients. We compared continuous tissue oxygenation measured by WiPOX between patients with anastomotic leaks and patients without anastomotic leaks and between patients with anastomotic strictures and patients without anastomotic strictures using the Wilcoxon rank sum test. Additionally, we examined the dichotomized version of tissue oxygenation level-the high oxygen saturation group (tissue oxygen saturation $>80 \%$; $n=93$ ) and the low oxygenation saturation group (tissue oxygen saturation $\leq 80 \% ; n=21$ ). The cutoff value of $80 \%$ was based on a prior pilot study that utilized the WiPOX device to take multiple measurements of tissue oxygenation on the mucosal and serosal surfaces of the gastric conduit in patients who were undergoing Ivor Lewis esophagectomies (17). The proportion of patients with anastomotic leak between the two groups was compared using Fisher's exact test. Statistical significance was set at $\mathrm{P}<0.05$. We also compared anastomotic leak rates between the study cohort and the cohort of patients who did not participate in the trial during the study period. These comparisons were completed using the Fisher's exact test. All statistical tests were performed using Stata 13 (Stata Corp., College Station, TX).

\section{Results}

During the study duration, we performed 185 Ivor Lewis esophagectomies; 2 were for benign disease, 1 was for GIST tumor, and the rest were for cancer. In our cohort, $75 \%$ of the patients received induction chemoradiation therapy and $3 \%$ received induction chemotherapy. Patient clinical and 
Table 3 Patient characteristics

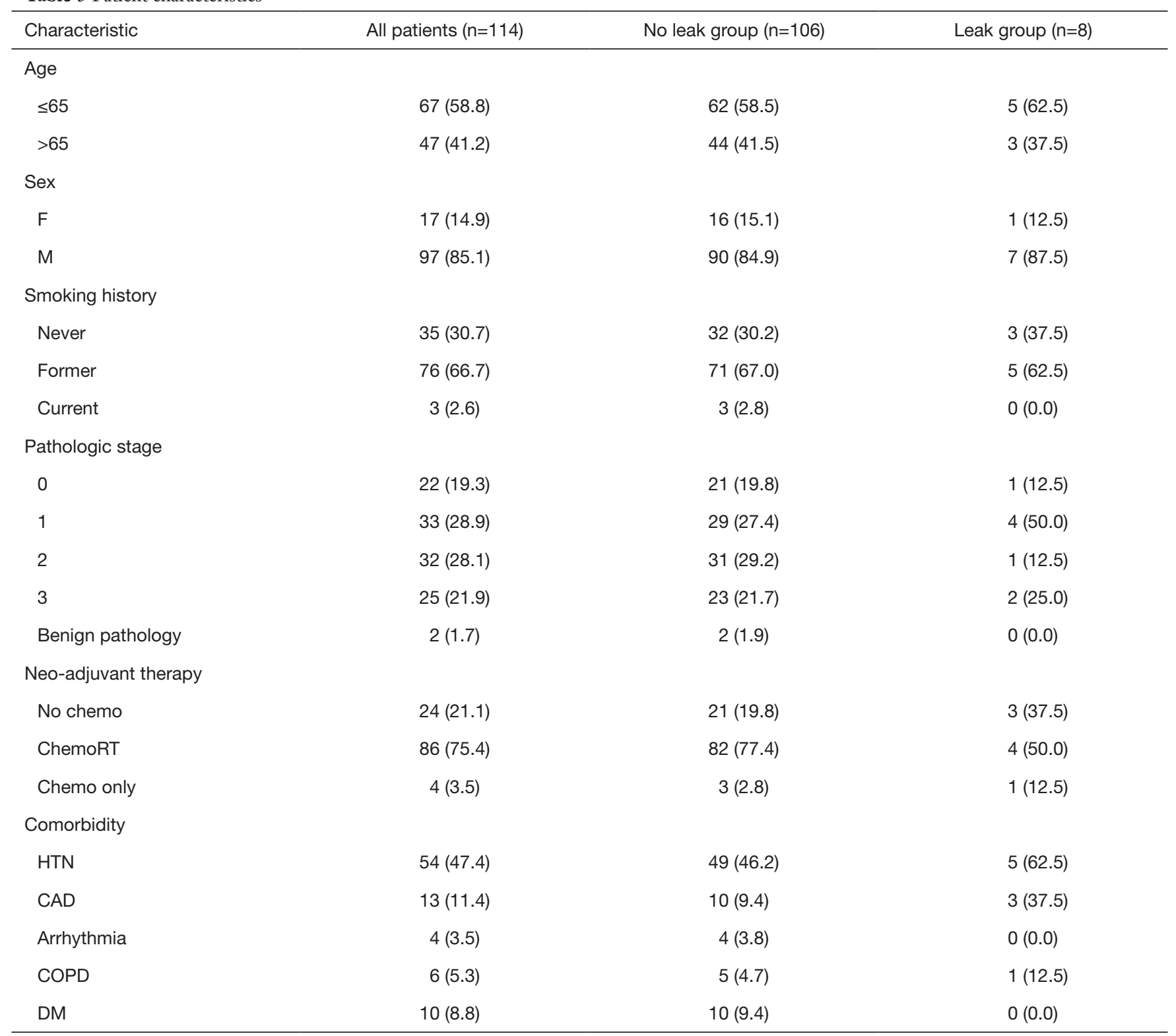

Data are No. (\%). CAD, coronary artery disease; COPD, chronic obstructive pulmonary disease; Chemo, chemotherapy; chemoRT, chemoradiotherapy; DM, diabetes mellitus; HTN, hypertension.

pathological characteristic are listed in Table 3. Sixty-nine patients were not included in our study because they either did not consent or the device was not available at the time of surgery. A total of 116 patients were accrued and only 2 patients were excluded. Among study participants, there was a positive correlation between systemic and WiPOXrecorded heart rate (Spearman's rho $=0.58 ; \mathrm{P}<0.001$ ).

Among the 114 patients who completed the study, there were $8(7.0 \%)$ anastomotic leaks and $3(2.6 \%)$ strictures observed. Median tissue oxygen saturation in patients with and without leaks was 98\% (range, 82-99\%) and 92\% (range, $84-98 \%$ ), respectively, and there was no statistically significant difference $(\mathrm{P}=0.2$; Figure 2$)$. Median tissue oxygen saturation in patients with and without strictures was $89 \%$ (range, 86-93\%) and 92\% (range, 83-98\%), respectively; there was no statistically significant difference $(\mathrm{P}=0.6)$. Among the 93 patients in the high tissue oxygenation group, 7 (7.5\%) had leaks, while no patients in 
the low oxygenation group ( $\mathrm{n}=21)$ had leaks $(0 \%)$; there was no statistically significant difference between the groups $(\mathrm{P}=0.3)$.

The difference in tissue oxygenation was not associated with clinical or demographic variables. There was a higher leak rate $(12 \%)$ among study non-participants who were undergoing an Ivor Lewis esophagectomy during the study period (Figure $3 A$ ). However, this difference was not statistically significant $(\mathrm{P}=0.3)$. The severity of leaks between study participants and non-participants did not differ (Figure 3B).

There was no correlation between systemic pulse oximetry and WiPOX-recorded oxygenation (Spearman's rho $=0.08, \mathrm{P}=0.4$, Figure $4 A$ ). There were no differences noted in gastric conduit tissue oxygenation between patients who received induction chemotherapy and those who did

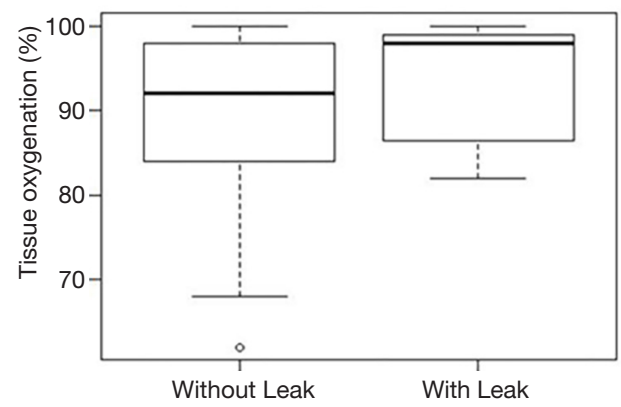

Figure 2 Median tissue oxygenation values in patients with and without anastomotic leak shown as a box plot.

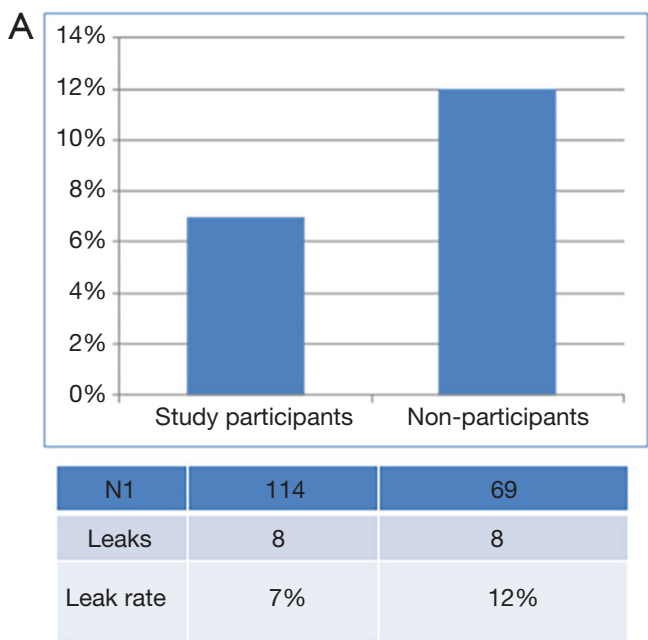

not $(\mathrm{P}=0.4$, Figure $4 B)$ and between patients who received induction radiation therapy and those who $\operatorname{did}$ not $(\mathrm{P}=0.1$, Figure 4C).

\section{Discussion}

In an effort to provide an objective real-time reading of tissue oxygenation at the point of interest for surgeons, we utilized the novel WiPOX device, which is based on pulse reflectance technology that, in prior trials, has been shown to provide accurate variations in tissue oxygenation values in both a porcine model (16) and a human pilot trial (17). While there have been prior publications that have investigated tissue oxygenation and its correlation to leaks in small retrospective studies (10-15), to date this is the first prospective clinical trial that has correlated tissue oxygenation values with anastomotic leaks and strictures. The strengths of our study are: (I) its prospective nature with the predefined objective of evaluating the association between tissue oxygenation levels and anastomotic leak rates and stricture formation; (II) a multi-surgeon participating investigation in a large cohort of patients with a comparable cohort that did not participate in the study; (III) real-time, intraoperative, objective assessment with a device that is optimized specifically for Ivor Lewis esophagectomies; and (IV) use of simultaneous intraoperative quality control measures such as heart rate measurement and wave form documentation. In addition, our study was the first to demonstrate that induction chemo- and/or radiation

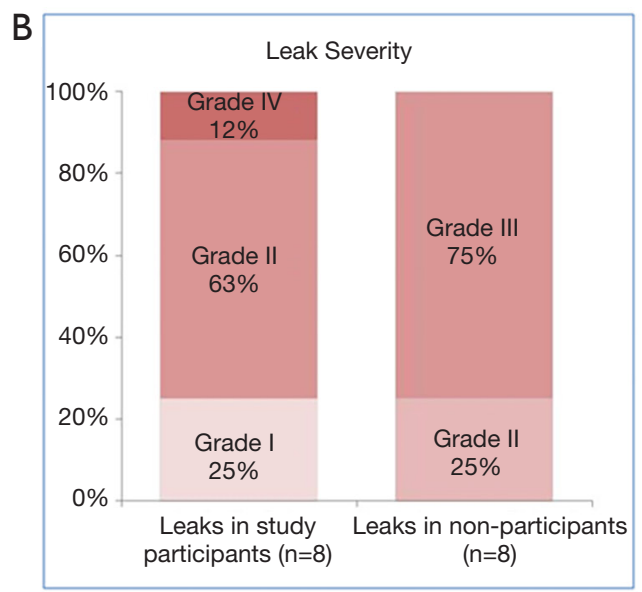

Figure 3 Anastomotic leak rates in study participants and non-participants (A) and the severity of anastomotic leaks graded according to standard Common Terminology Criteria for Adverse Events (CTCAE) v4.0 criteria in study participants and non-participants (B). 

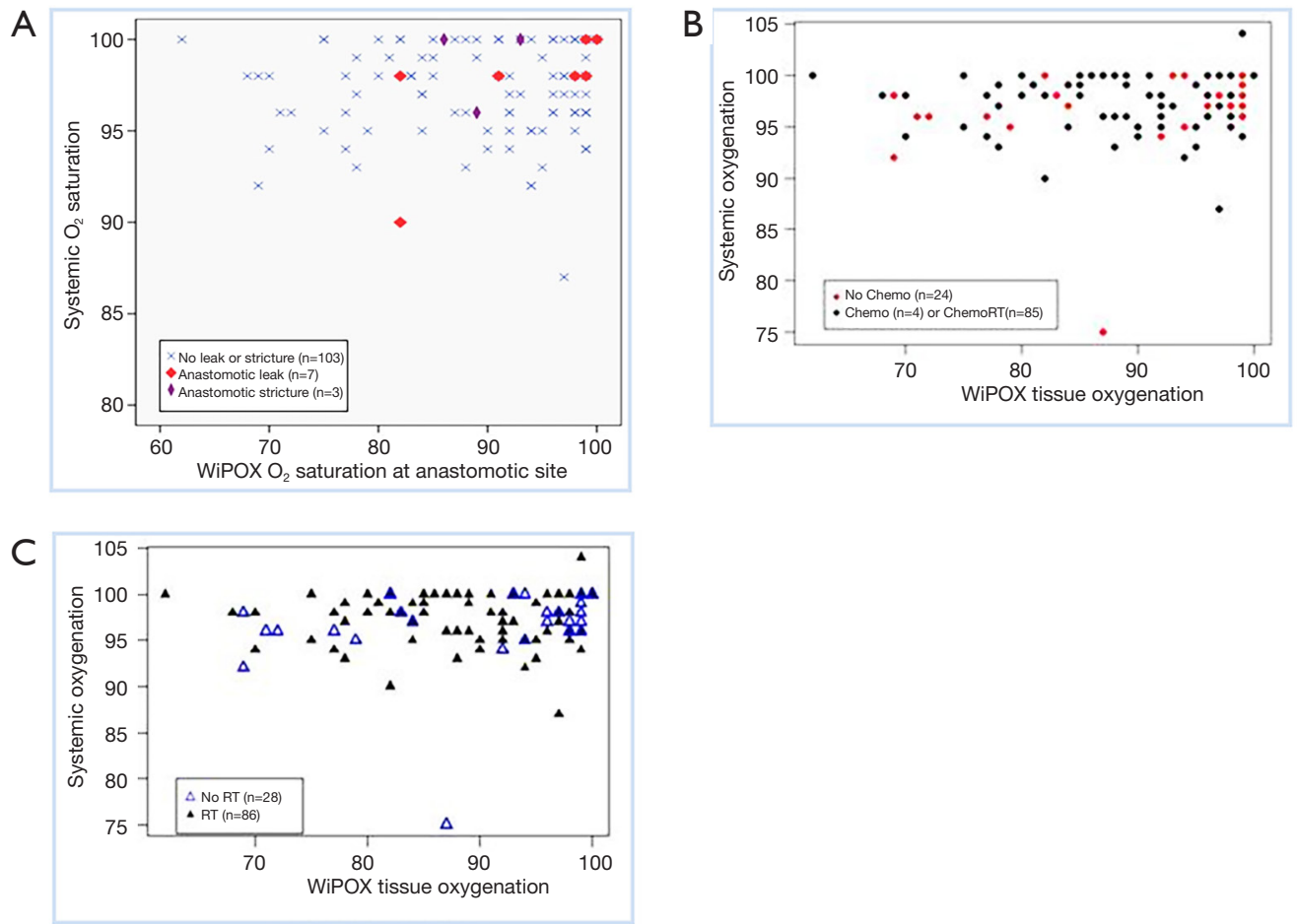

Figure 4 Systemic oxygenation does not reflect gastric conduit tissue oxygenation (A). There are no differences in gastric conduit tissue oxygenation among patients who received induction chemotherapy and those who did not (B). There are no differences in gastric conduit tissue oxygenation among patients who received induction radiation therapy and those who did not (C).

therapy does not influence tissue oxygenation.

Anastomotic leaks following esophagectomies with gastric conduit pull-up are thought to be more common because reconstruction requires ligation of 3 of the 4 vessels that provide the blood supply to the conduit, thus leaving only the right gastroepiploic artery for perfusion. Additionally, vagotomy was also shown to decrease tissue oxygenation (18). Postmortem examination of gastric conduits in post-esophagectomy patients showed that the blood supply of the proximal $20 \%$ of the gastric conduit was through a microscopic network of capillaries and arterioles (19). Ischemia of the gastric conduit due to altered arterial inflow and venous drainage has been implicated in high anastomotic leak rates and poor outcomes (19-23). Our group has previously published that technical complications have a negative impact on survival after esophagogastrectomy for cancer (1). In a study of 150 patients, $27 \%$ had complications directly attributable to surgical technique and $21 \%$ of patients had anastomotic leaks. At 3 years, $31 \%$ of the patients who had technical complications were still alive, compared with
$48 \%$ of patients without technical complications. Technical complications were associated with increased length of stay, increased in-hospital mortality, and higher rate of medical complications. After controlling for age, medical comorbidities, use of induction therapy, tumor stage, histology, location, and completeness of resection, presence of a technical complication was highly predictive of poorer overall survival (1).

Surgeons are trained to avoid technical complications by ensuring adequate perfusion to both edges of the anastomosis and minimizing the tension on the anastomosis. To date, these factors are evaluated only by surgeon visual inspection. Prior studies have indicated that perfusion may be compromised despite the anastomosis appearing visually healthy (9). There have been several studies that have investigated gastric conduit perfusion by use of Doppler ultrasound (10) and IV fluorescent dye (9). These methods of assessing gastric conduit perfusion are subjective and do not give direct tissue oxygenation values. Laser Doppler flowmetry has demonstrated significant decreases in blood flow to the distal gastric conduit after division of the short and left gastric vessels in patients 
who were undergoing esophagectomy (11). However, lack of data on sensitivity and specificity of laser Doppler flowmetry have limited its routine use for intraoperative assessment of visceral perfusion. Interestingly, using laser Doppler flow measurement, Schilling et al. (11). noticed that in patients with distal esophageal cancer or tumor involvement of the cardia, blood flux in the cardiac area was 2.5 to 3.5 times higher than in patients without tumor involvement of the cardia; this was speculated to be due to tumor-induced neovascularization. Dissection of the greater curvature and left gastric artery decreased blood flux at the proximal part of the greater curvature to a higher degree in patients without tumor infiltration of the cardia compared with patients with tumor infiltration of the cardia. They also observed that stretching of the gastric conduit further reduces microperfusion (11).

Our findings failed to show a statistically significant difference in tissue oxygenation between patients who had anastomotic leaks and those who did not; this was also true for stricture formation. Furthermore, there were no anastomotic leaks or strictures in the low tissue oxygenation group. These observations counter the assumption that intraoperative conduit poor tissue perfusion is an important factor in the development of anastomotic leaks or strictures. That we did not notice a difference in tissue oxygenation between the groups and that overall trial participants had lower anastomotic leak rates than non-participants indicates one of two falsenegative possibilities: either (I) there was inefficient surgeon blinding and the attending surgeons modified their anastomotic site based on the WiPOX measurement or (II) there may have been a Hawthorne effect at play where the anastomosis during the trial period was constructed with additional attention. Although the above assumptions cannot be validated, we observed that over a period of 2 years following completion of the study, the anastomotic leak rates went back up to the pre-study levels. Similar observations have been reported by other investigators. Campbell et al. performed intraoperative vascular evaluation with a combination of indocyanine green fluorescence imaging and Doppler examination of the gastric conduit to assist reconstruction after esophagectomy (10). After introduction of intraoperative vascular evaluation of the gastric conduit, the authors reported a decrease in anastomotic leak rates from $20 \%$ in the first 60 patients to $0 \%$ in the succeeding 30 patients. Although the reported results were dramatic, the report is retrospective in nature with no control cohort and the authors report an increase in leak rate in the subsequent 30 patients, attributing the increased anastomotic leak rate to performing surgery on more complicated patients (10).

One limitation of our study was that the study leak rate was lower than that observed in the pilot study. Future studies should take the variation in leak rate into calculation when determining the power of the study. Another limitation is the lack of continuous measurement of tissue oxygenation in the post-operative period. This would require leaving a probe or a sensor inside the mucosa for continuous measurement of tissue oxygenation, which in addition to regulatory hurdles poses the practical difficulty of interference of the measurement by gastric conduit fluids. One study by Jacobi et al. used this approach to measure tissue oxygenation during and after the surgical procedure and measured submucosal tissue oxygen tension $\left(\mathrm{PtO}_{2}\right)$ in 33 patients with cervical esophagogastrostomy using a Clark-type oxygen electrode (15). During the procedure, there was no significant evidence of decreased $\mathrm{PtO}_{2}$ levels in groups with and without anastomotic leaks. By contrast, postoperative $\mathrm{PtO}_{2}$ levels showed a significant increase in patients with anastomotic leakage. Since the $\mathrm{PaO}_{2}$ remained constant with increases in $\mathrm{PtO}_{2}$, the authors hypothesize that a disorder in oxygen consumption may cause a significant increase of $\mathrm{PtO}_{2}$ in anastomotic tissue, which is associated with anastomotic leakage. In multiple studies, post-operative leaks have been most commonly observed at day 4-7, leading to speculation that perhaps post-operative venous congestion of the conduit reciprocally compromises the arterial microperfusion, thereby decreasing tissue oxygenation and anastomotic leaks.

To simultaneously measure oxygen saturation $\left(\mathrm{SaO}_{2}\right)$ and blood volume fraction, and thereby potential venous congestion, Pham et al. conducted a study of optical fiber spectroscopy of the distal gastric conduit at baseline and after gastric devascularization, conduit formation, and transposition in 23 patients who were undergoing esophagectomy, 4 of whom previously had undergone gastric ischemic conditioning (12). This method assesses blood oxygenation in the gastric conduit by spectral analysis of shifts between unbound and oxygen bound hemoglobin molecules. They observed that $\mathrm{SaO}_{2}$ decreased and tissue blood volume fraction increased with successive division of the short gastric, left gastric, and conduit completion; however, these increases were not statistically significant. Conversely, after transposition of the gastric conduit, blood volume fraction increased by $53 \%$ above baseline and $\mathrm{SaO}_{2}$ returned to baseline levels. Comparing $\mathrm{SaO}_{2}$ and blood 
volume fraction in patients who had undergone ischemic conditioning with patients who did not, conditioned conduits showed a nonsignificant trend toward higher $\mathrm{SaO}_{2}$ and lower blood volume fractions. Unlike our study, 78\% of the study participants in this study had undergone cervical transposition, which produced a significant increase in tissue blood content that was thought to be due to venous congestion. The significant technical limitation of the spectroscopy system is that the collected data can only be analyzed post hoc and cannot be used to guide real-time decision making. Also, the effect of pressure on tissue and degree of tissue apposition on measurements were not optimized.

Unlike the other devices discussed above, the WiPOX device we developed and optimized can reliably measure intraoperative tissue oxygenation in a large cohort of patients. This novel device can be used to objectively measure tissue oxygenation during colon or small bowel interposition procedures, assess differential intestine saturation in patients being explored for ischemic bowel resection, and assess intraoperative tissue flap oxygenation. Furthermore, with growing use of robotic surgery where there is no tactile or visual feedback of anastomotic tension or tissue oxygenation, the WiPOX device can be incorporated into robotic fingers to measure tissue oxygenation.

In this prospective, single institution, multiple surgeonparticipating trial of patients who were undergoing Ivor Lewis esophagectomies, utilizing an intraoperative WiPOX device to measure tissue oxygenation directly at the anastomotic site, we did not observe a statistically significant difference in tissue oxygenation levels between patients who had anastomotic leaks or stricture formation and those who did not develop those complications. Future studies with measurements of serial tissue oxygenation in the postoperative period may shed light on compromised tissue oxygenation resulting from arterial perfusion deficiency and/or venous congestion that may result in anastomotic leaks.

\section{Acknowledgments}

Funding: This clinical trial is partly supported by a grant from the Esophageal Cancer Education Foundation. PS Adusumilli's laboratory work is supported by grants from the National Institutes of Health (U54 CA137788, P30 CA008748, R01 CA236615-01, and R01 CA235667), the U.S. Department of Defense (BC132124, LC160212, CA170630, and CA180889), the Batishwa Fellowship, the Comedy vs. Cancer Award, the Druckenmiller Center for Lung Cancer Research Fellowship, the Emerson Collective
Cancer Research Fund, the Esophageal Cancer Education Foundation, the Memorial Sloan Kettering Technology Development Fund, the Miner Fund for Mesothelioma Research, the Mr. William H. Goodwin and Alice Goodwin, the Commonwealth Foundation for Cancer Research, and the Experimental Therapeutics Center of Memorial Sloan Kettering Cancer Center.

\section{Footnote}

Conflicts of Interest: All authors have completed the ICMJE uniform disclosure form (available at http://dx.doi. org/10.21037/jtd.2020.02.58). PSA and MB have a pending patent application US20170172477A1 (wireless pulseoximetry device). PSA has received research funding from ATARA Biotherapeutics and OSE Immunotherapies; has received research fees from ATARA Biotherapeutics; has an issued patent 10,538,588 licensed to Atara Biotherapeutics, EP1979000B1, and pending patent applications WO2018165228A1, CA3034691A1, CA3007980A1, and AU2016316033A1. PSA serves as an unpaid editorial board member of Fournal of Thoracic Disease from Sep 2018 to Aug 2020. ISS serves as an unpaid editorial board member of Fournal of Thoracic Disease from Sep 2018 to Aug 2020. The other authors have no conflicts of interest to declare.

Ethical Statement: The authors are accountable for all aspects of the work in ensuring that questions related to the accuracy or integrity of any part of the work are appropriately investigated and resolved. Our prospective clinical trial (IRB\# 11-192) was approved by the Institutional Review Board of Memorial Sloan Kettering Cancer Center. Informed consent was obtained from all prospective patients.

Open Access Statement: This is an Open Access article distributed in accordance with the Creative Commons Attribution-NonCommercial-NoDerivs 4.0 International License (CC BY-NC-ND 4.0), which permits the noncommercial replication and distribution of the article with the strict proviso that no changes or edits are made and the original work is properly cited (including links to both the formal publication through the relevant DOI and the license). See: https://creativecommons.org/licenses/by-nc-nd/4.0/.

\section{References}

1. Rizk NP, Bach PB, Schrag D, et al. The impact of 
complications on outcomes after resection for esophageal and gastroesophageal junction carcinoma. J Am Coll Surg 2004;198:42-50.

2. Andreou A, Biebl M, Dadras M, et al. Anastomotic leak predicts diminished long-term survival after resection for gastric and esophageal cancer. Surgery 2016;160:191-203.

3. Markar S, Gronnier C, Duhamel A, et al. The impact of severe anastomotic leak on Long-term survival and cancer recurrence after surgical resection for esophageal malignancy. Ann Surg 2015;262:972-80.

4. Kofoed SC, Calatayud D, Jensen LS, et al. Intrathoracic anastomotic leakage after gastroesophageal cancer resection is associated with increased risk of recurrence. J Thorac Cardiovasc Surg 2015;150:42-8.

5. Luketich JD, Pennathur A, Franchetti Y, et al. Minimally invasive esophagectomy: results of a prospective phase II multicenter trial-the eastern cooperative oncology group (E2202) study. Ann Surg 2015;261:702-7.

6. Law S, Fok M, Chu KM, et al. Comparison of hand-sewn and stapled esophagogastric anastomosis after esophageal resection for cancer: a prospective randomized controlled trial. Ann Surg 1997;226:169-73.

7. Gronnier C, Trechot B, Duhamel A, et al. Impact of neoadjuvant chemoradiotherapy on postoperative outcomes after esophageal cancer resection: results of a European multicenter study. Ann. Surg 2014;260:764-70; discussion 670-1.

8. Sheridan WG, Lowndes RH, Young HL. Tissue oxygen tension as a predictor of colonic anastomotic healing. Dis Colon Rectum 1987;30:867-71.

9. Foppa C, Denoya PI, Tarta C, et al. Indocyanine green fluorescent dye during bowel surgery: are the blood supply "guessing days" over? Tech Coloproctol 2014;18:753-8.

10. Campbell C, Reames MK, Robinson M, et al. Conduit vascular evaluation is associated with reduction in anastomotic leak after esophagectomy. J Gastrointest Surg 2015;19:806-12.

11. Schilling MK, Redaelli C, Maurer C, et al. Gastric microcirculatory changes during gastric tube formation: assessment with laser Doppler flowmetry. J Surg Res 1996;62:125-9.

12. Pham TH, Perry KA, Enestvedt CK, et al. Decreased conduit perfusion measured by spectroscopy is associated with anastomotic complications. Ann Thorac Surg 2011;91:380-5.

13. Karliczek A, Benaron DA, Baas PC, et al. Intraoperative assessment of microperfusion with visible light spectroscopy for prediction of anastomotic leakage in colorectal anastomoses. Colorectal Dis 2010;12:1018-25.

14. Gareau DS, Truffer F, Perry KA, et al. Optical fiber probe spectroscopy for laparoscopic monitoring of tissue oxygenation during esophagectomies. J Biomed Opt 2010;15:061712.

15. Jacobi CA, Zieren HU, Zieren J, et al. Is tissue oxygen tension during esophagectomy a predictor of esophagogastric anastomotic healing? J Surg Res 1998;74:161-4.

16. Servais EL, Rizk NP, Oliveira L, et al. Realtime intraoperative detection of tissue hypoxia in gastrointestinal surgery by wireless pulse oximetry. Surg Endosc 2011;25:1383-9.

17. Colovos C, Rizk NP, Singh N, et al. Real-time intraoperative tissue oxygenation monitoring by wireless pulse oximetry (WiPOX) to assess gastric conduit oxygenation during esophagogastrectomy: A prospective feasibility study. J Am Coll Surg 2011;213:S45.

18. Sheridan WG, Lowndes RH, Lewis MH, et al. Oxygenation in the stomach and the effect of truncal vagotomy. Br J Surg 1991;78:937-9.

19. Liebermann-Meffert DM, Meier R, Siewert JR. Vascular anatomy of the gastric tube used for esophageal reconstruction. Ann Thorac Surg 1992;54:1110-5.

20. Urschel JD. Esophagogastrostomy anastomotic leaks complicating esophagectomy: A review. Am J Surg 1995;169:634-40.

21. Boyle NH, Pearce A, Hunter D, et al. Scanning laser Doppler flowmetry and intraluminal recirculating gas tonometry in the assessment of gastric and jejunal perfusion during oesophageal resection. Br J Surg 1998;85:1407-11.

22. Schröder W, Stippel D, Beckurts KT, et al. Intraoperative changes of mucosal pCO2 during gastric tube formation. Langenbeck's archives of surgery. Langenbecks Arch Surg 2001;386:324-7.

23. Schröder W, Beckurts KT, Stahler D, et al. Microcirculatory changes associated with gastric tube formation in the pig. Eur Surg Res 2002;34:411-7.

Cite this article as: Adusumilli PS, Bikson M, Rizk NP, Rusch VW, Hristov B, Grosser R, Tan KS, Sarkaria IS, Huang J, Molena D, Jones DR, Bains MS. A prospective trial of intraoperative tissue oxygenation measurement and its association with anastomotic leak rate after Ivor Lewis esophagectomy. J Thorac Dis 2020;12(4):1449-1459. doi: 10.21037/ jtd.2020.02.58 